\title{
E@: red social para la educación artística abierta y a distancia, para la formación continua del profesorado
}

\author{
Ángeles SAURA PÉREZ \\ Universidad Autónoma de Madrid \\ angeles.saura@uam.es
}

Recibido: $10 / 10 / 2012$

Aceptado: 23/01/2013

\begin{abstract}
Resumen
Al abordar el arte contemporáneo, encontramos una continua mutabilidad de contenidos, procedimientos y recursos. El acrónimo E@ hace alusión a una enseñanza- aprendizaje artística enfocada desde lo emocional, usando las tecnologías de información y comunicación . El grupo de investigación UAM: PR007 (Investigación de recursos Digitales para la Enseñanza Artística) usa las TIC para la formación continua del profesorado, trabajando colaborativamente y usando las redes sociales. La educación artística con TIC prepara a todo tipo de estudiantes a vivir en un mundo cada vez más complejo, lleno de incertidumbre. Para ello se adoptan características comunes al desarrollo de un proyecto artístico de arte contemporáneo en el que importa más el proceso que el resultado y éste es valorado en función de criterios de originalidad y creatividad.
\end{abstract}

Palabras clave: arte, educación, TIC, internet, redes sociales

\section{E@: social network for arts education free access and distance learning, for continuous teacher education}

\begin{abstract}
In addressing contemporary art, we find a continuous mutability of content, procedures and resources. E (a): The acronym refers to a focused artistic teaching and learning from the emotional, using information and communication technologies. The research group UAM: PR-007 (Digital Research Resource for Artistic Education) uses ICT for teacher education, working collaboratively and using social networks. Arts education with ICT prepares all students to live in an increasingly complex world, full of uncertainty. This will take features common to the development of an art project of contemporary art in the process matters more than the result and this is assessed based on criteria of originality and creativity.
\end{abstract}

Keywords: art, education, ICT, internet, social networking

\section{Referencia normalizada}

SAURA PÉREZ, Ángeles (2013): “E@: red social para la educación artística abierta y a distancia, para la formación continua del profesorado". Estudios sobre el Mensaje Periodístico. Vol. 19, Núm. especial marzo, págs.: 459-468. Madrid, Servicio de Publicaciones de la Universidad Complutense.

Sumario: 1. Introducción. concepto E@; 1.1. ArtEducación con TIC: uso de internet y las redes sociales para la enseñanza abierta a distancia. 2. Metodología; 2.1. Objetivos generales del proyecto. 3. E@: red social para la educación artística abierta y a distancia, para la formación continua del profesorado; 3.1. Educación artística en clave 1.0, 2.0, 3.0 y 4.0; 3.2. Formación informal del profesorado; 3.3. Uso de internet para la formación artística: Proyecto artEducación. 4. Conclusiones. 5. Referencias bibliográficas.

\section{Introducción: concepto E@}

El acrónimo E@ hace alusión a una enseñanza- aprendizaje artística enfocada desde lo emocional, usando las tecnologías de información y comunicación (en adelante 
TIC). Desde nuestro punto de vista la educación artística debe adoptar características comunes al desarrollo de un proyecto artístico de arte contemporáneo en el que importa más el proceso que el resultado y es valorado en función de criterios de originalidad y creatividad. El mensaje para la comunicación artística tiene forma de imagen y muchas veces formato multimedia. Dado que la imagen multimedia es el lenguaje del arte y de la comunicación por excelencia en internet y usado por todos y todas para el ejercicio de la acción docente, el binomio arte-educación cobra especial relevancia hoy.

La escuela ofrece un potencial de mejor conocimiento de sí mismo y de la realidad a los individuos. Si tenemos en cuenta el papel de la cultura visual en la vida cotidiana y en las representaciones que los artistas utilizan para representar nuestra relación con la realidad, es posible desarrollar diferentes estrategias pedagógicas al trasladarla a diferentes contextos educativos (Hernández, 2008: 78).

En nuestras visitas a centros de enseñanza primaria y secundaria para el seguimiento de las prácticas de nuestros estudiantes (futuros maestros) observamos que suele haber una gran distancia entre lo que se enseña en la escuela y los referentes culturales cotidianos de los niños y niñas o adolescentes. Según Hernández, la cultura es un conjunto de valores, creencias y significados que usan nuestros alumnos para dar sentido al mundo en que viven. Tomar ejemplos de imágenes, de la cultura que nos rodea (sin diferenciar alta o baja cultura), tiene la función de aprender a interpretarlos desde diferentes puntos de vista y favorecer la toma de conciencia de los alumnos sobre sí mismos y el mundo del que forman parte.

Desde una perspectiva escolar, como fundamento teórico del Área Artística, podemos tomar a la "Educación por el Arte", teoría sustentada por Herbert Read ${ }^{1}$, que propone no hacer de todos los individuos artistas, sino acercarles los lenguajes de las disciplinas artísticas que les permitan nuevos y distintos modos de comunicación y expresión, desarrollando las competencias individuales interrelacionadas con lo social, a través de la sensibilización, la experimentación, la imaginación, y la creatividad.

Nos hemos preguntado ¿cómo podrían llegar a ser más eficaces el profesorado y los profesionales de la Educación Artística? ¿cómo se diseña y organiza el aprendizaje del alumnado de artes visuales, cómo es llevado a cabo, y cómo se evalúa según los diferentes modelos educativos actuales? ( Marín, 2011: 221), nuestra respuesta se resume en lo que denominamos en su conjunto ArtEducación con TIC.

1 Read, Herbet: Poeta inglés, considerado como una autoridad en materia de Historia y Filosofía del Arte, ha derivado sus estudios hacia otros campos como el de la Educación, la Sociología,y la Historia de la Cultura. En su libro “Arte y Educación" ( 1991) su tesis se basa en vivificar la formulada por primera vez por Platón que promueve la idea de que el arte debe ser la base de toda forma de educación natural y enaltecedora. Para ello se dedica a aclarar conceptos fundamentales: Educación y Arte y la relación de ambos con la formación durante todas las etapas evolutivas del hombre. 


\subsection{ArtEducación con TIC: uso de internet y las redes sociales para la enseñanza abierta a distancia}

"Mejorar el nivel educativo de los ciudadanos supone abrirles las puertas a puestos de trabajo de alta cualificación lo que representa una apuesta por el crecimiento económico y por conseguir ventajas competitivas en el mercado global. En la esfera individual, supone facilitar el desarrollo personal y la integración social." (Anteproyecto de Ley Orgánica para la mejora de la calidad educativa, 2012: 1).

El contexto donde se desarrolla nuestro proyecto de innovación ArtEducación con TIC denominado abreviadamente como nuestra red social E@, es la Facultad de Formación del Profesorado y Educación de la Universidad Autónoma de Madrid. El Departamento de Educación Artística, Plástica y Visual cuenta desde 2004 con dos pizarras Digitales Interactivas en sus respectivos laboratorios de arte. Se desarrolla desde el grupo de investigación UAM: PR- 007 (Investigación de recursos Digitales para la Enseñanza Artística). Trabajamos en la formación continua del profesorado de enseñanzas artísticas colaborativamente, desde nuestra red social E@.

Nos planteamos que una educación artística es muy adecuada para preparar a todo tipo de estudiantes a vivir en un mundo cada vez más complejo (Saura, 2005: 231). Estamos en crisis, necesitamos trabajar en medio de la incertidumbre, aceptando con naturalidad una continua mutabilidad de contenidos, procedimientos y recursos. De hecho, en muchos campos estructurados de forma compleja los individuos se enfrentan a dificultades similares de aprendizaje (Efland, 2002: 119). Esto trae consigo a necesidad de una formación continua a lo largo de toda la vida laboral.

A la red social E@ se accede desde el enlace:www.arteweb.ning.com. Desde ella, se desarrollan diversos talleres artísticos en formato digital, on-line. El uso de ese espacio de relación docente, pero informal, permite a sus usuarios poner en práctica muchas ideas relacionadas con el "aprender -haciendo". Las experiencias desarrolladas están recogidas de manera más extensa en el libro titulado Innovación educativa con TIC en Educación Artística, Plástica y Visual. Líneas de investigación y estudios de casos (Saura, 2011). Entendemos la educación artística, visual, como necesaria para el desarrollo del autoconocimiento, la investigación, el reciclaje, el desarrollo de la percepción visual, el análisis y la creación de imágenes plásticas, para aprender Historia del Arte, para la experimentación, para el desarrollo del sentido de la estética, para el aprendizaje del trabajo en equipo, para el desarrollo de la creatividad, para trabajar la interculturalidad y la expresión creativa, para la comprensión del arte contemporáneo, para la formación en valores, para la crítica social y contra la violencia de género, entre otras. Todas las propuestas disponen de su propio espacio web, en formato blog. Sirvan como ejemplo las que se pueden consultar en los siguientes enlaces:

- Blog Variaciones en clave: http://variacionesenclave.blogspot.com/

- Blog Modelos con estilo.:http://modelosconestilo.blogspot.com/

- Blog Cómic en clave 2.0: http://artenlacescomic.blogspot.com/

- Blog Títere-TIC: http://uamtiteresymarionetas.blogspot.com

- Blog Golpe de efecto: http://artenlaces-golpedefecto.blogspot.com/

- Blog Desmontando Dibujos: http://investigodibujosanimados.blogspot.com/ 


\section{Metodología}

Promovemos el aprendizaje colaborativo, por grupos a partir del trabajo por proyectos donde confluyen las siguientes tres disciplinas: la Expresión Plástica, las Ciencias Sociales, la Lengua y la Literatura. Fomentamos un acercamiento crítico a los varios postulados teóricos que se aportan sin excluir las exposiciones magistrales mediante vídeo- conferencias cuando la materia lo pueda requerir. Para lograr los objetivos que se plantean las variadas asignaturas que impartimos, se emplea una metodología activa que, según los casos y posibilidades está basada en el aprendizaje en movilidad o mobile learning. Nuestro paradigma educativo se basa en artefactos tecnológicos portables como Mp3, PDA, iPad y eBooks, entre otros. De este modo, pretendemos demostrar el uso y las posibilidades educativas de estos aparatos tan cotidianos entre los jóvenes del S. XXI. Partiendo de la educación, la sensibilidad y el respeto, se empiezan a contemplar como una herramienta didáctica más, con absoluta naturalidad.

\subsection{Objetivos generales del proyecto}

Pretendemos colaborar en el desarrollo de las competencias culturales y artísticas de todo tipo de profesores de enseñanzas artísticas, usuarios de nuestra Red E@, de forma abierta y a distancia. Desde que en 1965 Noam Chomsky, en su artículo Aspects of theory of syntax, introdujera el término competencia en el ámbito de la educación todos aquellos interesados en la enseñanza hemos tenido que reflexionar sobre las múltiples acepciones y confusas definiciones y conceptualizaciones de las mismas. Entendemos la competencia como capacidad. Esto implica que los usuarios aprenden no solo informaciones, sino que serán capaces de saber que puede hacer con esos conocimientos, donde aplicarlos, cómo hacerlo, porqué usarlos o porqué no.

Los usuarios de nuestro espacio competirán mejor y podrán mostrar un mejor nivel de desarrollo profesional, artístico y docente. Hemos dado un paso hacia adelante, hemos entrado en la sociedad de la imaginación (Martín, 2012:27) donde el arte y la educación van de la mano dando formato al nuevo contexto docente, la nube $e^{2}$.

\section{E@: red social para la educación artística abierta y a distancia, para la for- mación continua del profesorado}

Vivimos un momento de transición digital (Caballero, 2008: 2), en él conviven dos estilos de enseñanza, el modelo anterior ( tradicional y caracterizado por el uso de la tiza) y otro nuevo, caracterizado por la incorporación del uso de TIC, desarrollado haciendo uso de pizarras digitales interactivas. El futuro ya está aquí y como dice Marc Prensky (Madrid, 2010) "Nuestros alumnos son como cohetes espaciales: van rápido, se lanzan de cabeza a lugares desconocidos, son muy volátiles, difíciles de controlar con precisión. Necesitan combustible, ser programados adecuadamente, necesitan correcciones de dirección a medio camino pero tienen un potencial de retorno enorme que es el que tenemos que descubrir. Cuando se nos pide que seamos especialistas en cohetes, la educación se convierte en una ciencia espacial".

2 Trabajamos en la nube; numerosos ordenadores conectados a través de Internet 
Algunos docentes viven la actualidad emocionados y divertidos porque son juguetones (lo son todos los nativos digitales), otros viven el momento asustados por tener que ponerse al mando de la nave espacial. Las herramientas están cambiando mucho y muy deprisa. En este momento no podemos olvidar que los docentes no somos simples herramientas y debemos servir a los estudiantes para prepararse los exámenes pero sobre todo para emocionarles y descubrir sus pasiones, solo así encontrarán su vocación y podrán trabajar y vivir felices en un futuro que aún nos es desconocido.

La Educación Artística con medios tradicionales (la mencionamos como EA), evoluciona hacia un nuevo estilo más adecuado al contexto de la sociedad actual. Vivimos en una aldea global y estamos enREDados (conectados a través de Internet) e infoxicados (intoxicados por exceso de información). El espacio artístico habitable está lleno de prosumidores ( gente que produce y consume imágenes constantemente). Como se ha mencionado, cuando en el proceso de enseñanza -aprendizaje de asignaturas artísticas hacemos uso de infraestructura informática y conexión a internet hablamos de E@. Los nuevos docentes deben estar preparados para practicarla con eficacia y los que estamos en activo debemos reciclarnos constantemente, conocer las nuevas herramientas y metodologías docentes para poder atender adecuadamente a los nuevos estudiantes.

\subsection{Educación artística en clave 1.0, 2.0, 3.0 y 4.0}

En el contexto español el proceso de incorporación de la tecnología informática a las escuelas se inició institucionalmente con el Proyecto "Atenea" impulsado por el Ministerio de Educación y Ciencia a mediados de los años ochenta. Desde entonces han sucedido muchas cosas en el panorama social y educativo que debemos conocer para entender cómo y por qué nos encontramos en 2010 trabajando en Escuelas 2.0, con aulas llenas de ordenadores y pizarras digitales interactivas. Siempre que el ser humano ha incorporado nuevos procedimientos de creación, el arte ha sufrido una gran cambio. Nos encontramos en una fase de clasicismo del arte posmoderno que es la que define, junto a su carácter tecnológico, una nueva cultura global. Esta crece extrañamente desdoblada entre el mundo real y el virtual, igual que nuestra actividad artística y docente.

Usamos el concepto de educación artística 1.0 haciendo referencia a la practicada utilizando como herramienta de comunicación docente la tiza sobre pizarra tradicional, el concepto 2.0 haciendo referencia al uso de la imagen en forma de presentaciones digitales sobre pizarra digital. Finalmente el concepto 3.0, haciendo referencia al uso de internet accediendo a través de la pizarra digital mencionada. No solamente como fuente de información sino como lugar de comunicación, usando las redes sociales y todo tipo de espacios colaborativos. Finalmente nos referimos al concepto 4.0, cuando hablamos de formación autodidacta a partir del uso de una internet dinámica que es capaz de interactuar con nosotros en función de nuestras preferencias y necesidades de formación (Escaño, 2010: 5). 


\subsection{Formación informal del profesorado}

Desde el año 2000, los profesores de enseñanzas artísticas de España en activo hemos vivido numerosos cambios en nuestra vida profesional. Cambiamos la máquina de escribir por el ordenador, comenzamos a escribir usando hipervínculos, palabras enlazadas a otros lugares del mismo documento o a internet, aprendimos a usar programas de dibujo digital, manejar programas de retoque de imagen, realizar presentaciones PowerPoint, escanear documentos, usar google y otros buscadores, preparar las clases usando bibliotecas virtuales de contenidos, usar pizarras digitales interactivas y cámaras de foto digitales. Hemos aprendido a hacer blogs y wikis, usar el web mail, usar el formato multimedia para comunicar con nuestros alumnos, utilizar nuevas metodologías didácticas haciendo uso de la infraestructura informática en las aulas y su conexión a internet, usar los móviles con cámara de fotos y vídeo, trabajar colaborativamente a través de internet usando google.doc (entre otros), redes sociales, la plataforma moodle y otras para la enseñanza abierta a distancia (de apoyo a las clases presenciales), e-learning (exclusivamente a través de la red) y m-learning ( a través del móvil), entre otros.

La formación del profesorado del área necesita del conocimiento de todos esos conceptos y una actualización permanente en lo que se refiere a contenidos, metodologías y herramientas tecnológicas (Brea, 2010: 24).

\subsection{Uso de internet para la formación artística: Proyecto artEducación}

Actualmente disponemos de importantes bibliotecas virtuales de enseñanza artística entre las que destacaremos las siguientes:

- Espiral Cromática de Pilar Toro

- EPV TIC Plástica de Lucía Álvarez

- ARTEnlaces de Ángeles Saura

Nosotros las usamos pero además, hemos trabajado un modelo de uso de las redes sociales. La plataforma ning denominada E@: Red de artistas-docentes, Educación artística en clave 3.0 se ha diseñado como medio de apoyo para los procesos de docencia, investigación, extensión y gestión de la información en el aula o fuera de ella. Atención, ya no es necesario ir a la escuela para aprender o para seguir aprendiendo.

A partir de los resultados iniciales de nuestra línea de investigación ( en el entorno UAM), se propuso ampliar la misma para el contexto Iberoamericano (Saura, 2010: 7). Después de intentar sin éxito crear un grupo de habla española insertada en la red americana http://arted20.ning.com/ se diseñó una red propia, de habla española. Con el aporte inicial de profesores de Brasil, Chile, Cuba, Venezuela y España se partió del mismo formato (ning). Actualmente participan representantes de casi todos los países de habla española y este espacio se ha constituido como referente del trabajo colaborativo en red para el colectivo mencionado de artistas- profesores. Al proyecto (patrocinado en sus inicios por el Banco Santander- UNIVERSIA- en colaboración con la Universidad Autónoma de Madrid), se unieron los profesores Carlos Sánchez Torrealba, de la Universidad Central de Venezuela; Fabio Rodrigues, de la Universidad Regional de Cariri, Brasil; Gerardo Borroto, del Instituto Superior Politécnico José Antonio Echevarria, de Cuba; Maria Emilia Sardelich, de la Universidad Metropolitana 
de Santos, Brasil; Nancy Iriarte Araya, de la Universidad de La Serena, Chile y Sybil Caballero, del Proyecto Tránsito Digital en el Ámbito Educativo, de Venezuela. A partir de la discusión de esos profesionales, relacionados por la tecnología de la web 2.0 se organizaron las I Jornadas Internacionales de Educación artística en clave 2.0 (Madrid, julio de 2009), se puso como objetivo general del grupo de investigación desarrollar redes de intercambio en Internet donde se pudiera pensar, reflejar, construir y deconstruir conocimiento sobre los problemas que nos deparara la práctica de la educación artística, en el contexto iberoamericano; fortalecer los intercambios y avanzar en la investigación educativa, favoreciendo los programas de formación inicial y continua en los profesores de educación artística. Apostamos por el desarrollo del trabajo colaborativo como metodología de investigación docente, para procurar la formación continua del profesorado y la atención a la diversidad.

A pesar de la crisis y la consecuente actual falta de patrocinio, se desea una continuidad en la línea de trabajo emprendida. Ya en estas nuevas condiciones, en el año 2011 se desarrollaron (en colaboración con Aulas Madrid Tecnología) las III Jornadas Internacionales de Educación Artística en clave 2.0. Se puede acceder a todas las comunicaciones presentadas desde el enlace siguiente: http://tercerajornadaeducacionartistica.blogspot.com.es/

Actualmente nuestro grupo de investigación está desarrollando ( en colaboración con la Red Iberoamericana de Educación Artística y el Ilustre colegio de Licenciados y Doctores en Belllas Artes de Madrid, las IV Jornadas Internacionales de Educación Artística en clave 2.0. La jornada de clausura consistirá en una reunión presencial que tendrá lugar en la Facultad de Formación del Profesorado y Educación de la Universidad Autónoma de Madrid. Se podrá acceder a todas las comunicaciones presentadas desde el enlace siguiente: http://cuartajornadaeducacionartistica.blogspot.com.es/

\section{Conclusiones}

El uso de TIC para las enseñanzas artísticas va en aumento por distintos motivos: existencia de infraestructura informática y conexión a internet de los centros educativos, incremento de recursos en formato digital; formación y reciclaje de los profesores y aumento de estrategias para integrarlas en el desarrollo curricular (Saura, 2011: 81). Desde los Departamentos de Dibujo de los centros y en todos los niveles educativos se imparten una gran cantidad de asignaturas muy diferentes entre si. Todas ellas pueden agruparse en dos grandes grupos: Dibujo Técnico y Expresión Artística. En el segundo, más amplio, impartimos Procedimientos artísticos, Dibujo Artístico, Pintura, Escultura, Grabado, Diseño, Educación Plástica y Visual (EPV), Imagen y Expresión, Fotografía o Comunicación Audiovisual (CAV), entre otras.

El uso de los medios informáticos se está integrando en el trabajo del profesorado de enseñanzas artísticas. Empezamos 2011 con nueva infraestructura informática (Pizarras digitales) y conexión a internet en la mayoría de los institutos públicos y colegios de la Comunidad de Madrid.

Existe un acuerdo general en que son tres los factores del contexto escolar que afectan a los resultados de los estudios sobre el asunto que nos ocupa: la infraestructura tecnológica; el total de alumnos del centro y el conocimiento que el profesor tiene 
de la tecnología. Encontramos otros factores. En concreto, hacen referencia a los elementos que influyen en la capacidad de un centro escolar para usar de forma efectiva la tecnología para el aprendizaje de los alumnos: liderazgo, objetivos de su Comunidad Autónoma y del centro, expectativas para el uso de la tecnología en el aula, clima y cultura del centro, creencias de los docentes sobre los alumnos y su potencial para el aprendizaje, desarrollo profesional del docente en el puesto de trabajo, experiencia previa del profesor con la tecnología y accesibilidad de los recursos tecnológicos (materiales y humanos) en el centro educativo. Adquiere cada vez más importancia la idea de que el uso de TIC aumenta las capacidades comunicativas, expresivas, analíticas y lógicas de los estudiantes. Esto es importante por dos razones, la primera porque apoyan formas de aprendizaje que serían difíciles de lograr por otras vías, tanto en la dimensión afectiva, como artística y conceptual, por ejemplo: establecer contacto con personas fuera del aula, revisar y reelaborar continuamente el trabajo original, sea escrito o en formato audiovisual. La segunda razón, porque pueden apoyar experiencias de aprendizaje que todos los alumnos deberían tener, como el acceso a material de fuentes de primera mano o la comunicación del trabajo propio a su grupo u otras audiencias diversas. Todo ello implica la necesidad de alfabetización visual y digital de alumnado y profesorado, de preguntarnos cómo se puede articular un modelo preciso de uso de infraestructura informática e internet para la mejora en el desarrollo de competencias culturales y artísticas de los alumnos y alumnas.

Se ha ido creando una infraestructura material con recursos cada vez más adecuados y se han desarrollado planes de formación docente en TIC, pero falta actualizar el currículum oculto de enseñanzas artísticas (Acaso, 2009: 55). Llama la atención la obsesión de los libros de texto de primaria y secundaria por el desarrollo de contenidos sobre dibujo técnico, el punto, la línea, la textura o el plano, tocando por encima aquellos que permiten el desarrollo de importantes competencias artísticas y culturales a los estudiantes relacionados con el autoconocimiento, la autoexpresión creativa, la cultura visual, la multi e interculturalidad, la capacidad crítica, la igualdad de género, la experiencia estética y el uso de los recursos del arte contemporáneo, entre otras.

Va siendo hora de que los centros demuestren el valor de la infraestructura con la que cuentan, antes de seguir invirtiendo en más recursos y más formación.

Los nuevos docentes tienen que ser como siempre fueron: vocacionales, expertos, responsables y comprometidos. Pero también tienen que saber estar enREDados (participar en alguna red social), saber ser invisibles (por trabajar en parte desde la red), ser juguetones y curiosos (así aprenden a usar las tecnologías los niños pequeños). Por último, para poder sacarle provecho didáctico a los nuevos recursos vayan conociendo, deben ser creativos. Los docentes de enseñanzas artísticas deben recordar siempre que se formaron como artistas, en las Facultades de Bellas Artes, Diseño o Arquitectura. Eso les permite ejercer la artEducación, en beneficio de toda la comunidad educativa. La imaginación y la creatividad son los instrumentos indispensables para desarrollar nuestra docencia. Los artistas, mejor que nadie, son capaces de sorprender, de conmover, percibir la realidad, trabajar en equipo y emprender acciones para comunicar y también para transformar el entorno docente, usando el lenguaje artístico. 


\section{Referencias bibliográficas}

ACASO LÓPEZ-BOSCH, María (2009): Nuevas prácticas en la enseñanza de las artes y la cultura visual. Madrid, Catarata.

BREA, José Luis (2010): Las tres eras de la imagen. Barcelona, Akal.

CABALLERO, Sybil (2008): Tránsito digital en el ámbito educativo" en Revista Iberoamericana de Educación. Nº48/6, pp. 1-13

EFLAND, Arthur (2002): Una historia de la educación del arte. Tendencias intelectuales y sociales en la enseñanza de las artes visuales. Barcelona, Paidós Arte y Educación.

ESCAÑO GONZÁLEZ, Carlos (2010): "Hacia una educación artística 4.0" en Revista Arte, individuo y sociedad, Vol. 22, No 1, pp. 135-144

HERNÁNDEZ HERNÁNDEZ, Fernando (2008): Espigadores de la cultura visual. Barcelona, Octaedro.

MARÍN VIADEL, Ricardo. (2011): "La Investigación en Educación Artística”, Educatio siglo XXI en Revista de la Facultad de Educación, No. 29, 1, pp. 211-230

MARTÍN PRADA, Juan. (2012): Prácticas artísticas e internet en la época de las redes sociales. Madrid, Akal.

SAURA PÉREZ, Ángeles (2005): Uso del diseño y la imagen tecnológica en las presentaciones multimedia para la comunicación audiovisual. Aplicación para la enseñanza artística. Tesis. Madrid, UCM.

SAURA PÉREZ, Ángeles (2011): Innovación educativa con TIC en Educación Artística, Plástica y Visual. Sevilla, Eduforma.

SAURA, Ángeles; NARANJO, Rosario; MÉNDEZ, Amador (2009): "Desarrollo de competencias en clave Web 2.0 para la educación artística" en Revista Relada, $n^{o}$ 3 (1), pp. 37-45: http://polired.upm.es/index.php/relada/article/viewFile/58/58 [fecha de consulta: 24 de julio de 2012 ] Madrid, ADA.

SAURA, Ángeles y SARDELICH, Maria Emilia (2010): "Interterritorialidades en web 2.0. Posibilidades para la formación continua del maestro de educación artística en el contexto latinoamericano" en Revista Iberoamericana de Educación $\mathrm{N}^{\mathrm{o}}$ 52/3:http://www.rieoei.org/3594.htm. [fecha de consulta: el 1 de julio de 2012]

2012, "Anteproyecto de Ley Orgánica para la mejora de la calidad educativa", versión 1: http://cort.as/2Yja_[fecha de consulta: 5 de septiembre de 2012 ] 


\section{Ángeles SAURA PÉREZ}

Universidad Autónoma de Madrid (UAM)

Artista. Doctora en Bellas Artes. Máster en Informática Educativa. Experta en Enseñanza Abierta a Distancia. Creadora de la Biblioteca Virtual de Enseñanza Artística ARTEnlaces (www.artenlaces.com) y de la Red social de artistas -docentes E@: Enseñanza artística en clave 3.0 (www.arteweb.ning.com). Profesora de Dibujo de Enseñanza Secundaria (1993-2008). Profesora Titular de Didáctica de la Enseñanza Artística, Plástica y Visual en la Facultad de Formación del Profesorado y Educación de la Universidad Autónoma de Madrid (UAM), desde 2008. Directora de la especialidad de Dibujo dentro del Máster de Enseñanza Secundaria impartido en la UAM. Autora del libro: Innovación educativa con TIC en Educación artística, Plástica y Visual (Sevilla: Eduforma, 2011)

angeles.saura@uam.es 